\title{
Do Resin Cements Alter Action Potentials of Isolated Rat Sciatic Nerve?
}

\author{
Ahmet Atila Ertan ${ }^{a}$ \\ Nilufer Celebi Beriat ${ }^{b}$ \\ Mehmet Ali Onurc \\ Gamze Tanc \\ Murat Cavit Cehrelid
}

\section{ABSTRACT}

Objectives: The purpose of this study was to explore the effects dual-cure resin cements on nerve conduction.

Methods: Panavia F, RelyX ARC, and Variolink II polymerized either by light-emitting diode (LED) or quartz tungsten halogen $(Q T H)$ were used in the study $(n=10)$. The conductance of sciatic nerves of 50 rats were measured before and after contact with the specimens for $1 \mathrm{~h}$.

Results: The time-dependent change in nerve conductance and the comparison of LED versus QTH showed that differences between groups are significant $(P<.05)$. For both polymerization techniques, pair-wise comparisons of resin cements showed that the nerve conductance between groups is different $(P<.05)$. RelyX ARC elicited irreversible inhibition of compound action potentials (more than 50\% change) and Panavia F and Variolink II polymerized by LED and QTH did not alter nerve conduction beyond physiologic limits.

Conclusions: Resin cements may alter nerve conductance and even lead to neurotoxic effects. (Eur J Dent 2011;5:199-205)

Key words: Resin cement; Light-emitting diode; Quartz tungsten halogen; Neurotoxicity; Rat; Sciatic nerve.

a Hacettepe University, Faculty of Dentistry, Department of Prosthodontics, Ankara, Turkey.

b Hacettepe University, School of Dental Technology, Ankara, Turkey.

c Hacettepe University, Faculty of Science, Department of Biology, Ankara, Turkey.

d CosmORAL Oral and Dental Health Polyclinics, Section of Prosthodontics, Ankara, Turkey.

- Corresponding author: Nilufer Celebi Beriat Hacettepe University, School of Dental

Technology, Sihhiye, 06100, Ankara, Turkey.

Phone: +90 3123051587

Fax: +903123102730

E-mail: nberiatฉhotmail.com

\section{INTRODUCTION}

A wide range of dental cements exists for luting of posts, inlays/onlays, composite/ceramic laminates, and fixed prostheses. Over the last decades, enthusiasm for the use of resin cements and resin modified glass ionomer cements was great for endodontic treatment and luting of restorations. At the margin of the restoration, cements may come into contact with soft tissues and fluids; since they may have adverse effects on the pulp, the biocompatibility of dental cements seems as 
important as their mechanical and physical properties. ${ }^{1,2}$

Dual-cure resin composites were developed to add the advantageous properties of chemically polymerizing and light-polymerizing materials, thereby providing sufficient polymerization in deeper zones with shorter polymerizing times., ${ }^{3,4}$ Nevertheless, resin-based materials and adhesives release several components into the oral environment such as considerable amounts of triethylene glycol dimethacrylate (TEGDMA), 2-hydroxy-ethyl-methacrylate (HEMA), and unbound resin components in the early phase after polymerization. The cements then continue to release materials due to degradation or erosion. ${ }^{1}$ These leachable materials cause apoptosis ${ }^{5-8}$ and have shown genotoxic and mutagenic effects ${ }^{9-12}$ and, therefore, may potentially have adverse effects on the pulp, gingiva, and apical tissue. ${ }^{13-17}$

In the context of biocompatibility, another critical issue that needs to be considered is whether these materials have neurotoxic effects. Recent evidence suggests that dentin bonding agents could significantly alter action potentials of nerves, thereby leading to irreversible adverse effects in the pulp. ${ }^{18,19}$ The success of polymerization depends on the thickness of the filling material, the wavelength of the excitation light, the power density, and time of irradiation. Tuning between excitation wavelength and the photoinitiator system has a decisive effect on the degree of polymerization. There are various types of light-curing units (LCU) in the dental market such as quartz tungsten halogen (QTH) and light-emitting diodes (LED) curing units. QTH units have been used to polymerize composite resin, but the drawback of the halogen unit is a declining irridiance over time due to aging lamps and filter. Increasingly, as an alternative to QTH, LED curing units are being used in dental practice. The LED has the advantages of extended lifetimes over $10000 \mathrm{~h}$, little degradation of light output over time, preventing and minimal overheating, resistance shock, or vibration. The spectral output of LEDs consists of the absorption peak of camphorquinone $(C Q$; 400$500 \mathrm{~nm}$, peak at $470 \mathrm{~nm}$ ), the most used photoinitiator in resin composites. Comparative studies demonstrated that the type of LCU is an important factor for both curing efficiency and generated heat. However, toxicity of the composites with dif- ferent curing methods has had relatively little investigation. The determination of the composite's possible toxic effect is a matter of interest. In view of the great variety of LCUs and resin materials currently in use, the question is which combinations cause the least toxic effects. At present, no evidence exists on the possible neurotoxic effects of resin cements. Therefore, the purpose of this study was to explore the effects of dual-cure resin cements polymerized by two different techniques on action potentials of isolated rat sciatic nerves.

\section{MATERIALS AND METHODS}

\section{Sample preparation}

Three different dual-cure resin cements - Panavia F (Kuraray Medical Inc., Tokyo, Japan), RelyX ARC (3M ESPE, Seefeld, Germany), and Variolink II (IvoclarVivadent, Schaan, Liechtenstein) - were used in this study (Table 1). Disc-shaped samples were prepared by using a teflon mold in $10 \mathrm{~mm}$ diameter and $1 \mathrm{~mm}$ thickness. Two Mylar bands were used to cover the unpolymerized resin cements, and the tip of light-curing units were placed directly over the Mylar band. Twenty samples were prepared from each cement and randomly allocated into two groups ( $n=10 /$ group) according to the light-curing unit used:

1. QTH/40seconds (Optilux 501, Kerr, Orange, CA);

2. LED/20 seconds (Elipar Freelight II, 3M/ ESPE, Seefeld, Germanyl.

Before photoactivation, the irradiance of both curing units was confirmed with QTH and LED radiometers (Kerr/Demetron, Orange, CA).

\section{Animals and care}

Fifty locally bred male Wistar rats weighing 300-330 g were used in this study. Prior to experiments, the animals were cared for according to the policies and principles established by the Animal Welfare Act and the NIH Guide for Care and Use of Laboratory Animals (Publication \# 86-23). All surgical procedures were performed under general anesthesia using a mixture of ketamin (Ketalar, Parke-Davis; 30 mg/kg i.m.) and xylazine (Rompun, Bayer; 10 mg/kg i.m.).

Measurement of compound action potentials

Bilateral sciatic nerves of the animals were dissected from the spinal cord to the knee, 
cleaned free from adherent tissue under a dissection microscope, and placed in a three-chambered recording Pyrex bath containing Tyrode solution 18 $\mathrm{g} / \mathrm{l} \mathrm{NaCl}, 0.2 \mathrm{~g} / \mathrm{l} \mathrm{KCl}, 0.2 \mathrm{~g} / \mathrm{l} \mathrm{CaCl}_{2}, 0.1 \mathrm{~g} / \mathrm{L} \mathrm{MgCl}_{2}, 1$ $\mathrm{g} / \mathrm{l} \mathrm{NaHCO}, 0.05 \mathrm{~g} / \mathrm{L} \mathrm{NaH}_{2} \mathrm{PO}_{4}$, and $1 \mathrm{~g} / \mathrm{l}$ glucose) kept at $37^{\circ} \mathrm{C}$ and continuously aerated with $\mathrm{O}_{2}$ and $\mathrm{CO}_{2}$ 195\% and $5 \%$, respectively). ${ }^{18-20}$ To keep the nerve tissue fresh and vital, the animal was kept under general anesthesia in a $25^{\circ} \mathrm{C}$ incubator while an experiment was carried out using the first sciatic nerve. The nerves were perfused with the Tyrode solution with a constant rate of $2 \mathrm{ml} / \mathrm{min}$ at $37^{\circ} \mathrm{C}$, and had a $\mathrm{pH}$ value of 7.4 . The nerves were mounted between the stimulating and the recording electrodes, and continuous pulses were delivered (pulse width: $0.049 \mathrm{msec}$; pulse rate 2.0) by a 0811A Pulse Generator (Hewlett Packard, Melrose, MA, USAl through a Schwarzer AK1W161B Stimulus isolation unit (Schwarzer $\mathrm{GmbH}$, Munich, Germany). The nerve signals were digitalized by a Biopac MP30 Data Acquisation System (Biopac Systems Inc., CA, USA) and displayed in a computer with corresponding software (Biopac Student Lab Pro 3.6.6.; Biopac Systems Inc., CA, USA) at a sample rate of $100 \mathrm{kHz} .{ }^{18-20}$ These values were used to establish the basal response (control) of each nerve before it was brought into contact with one of the test materials. The amplitude of the evoked compound action potentials (cAPs), the time required for initiation of compound action po- tentials (TcAP), depolarization (Dp), and repolarization (Rp) were recorded before and for up to 60 minutes after contact with the resin cements.

\section{Statistical analysis}

Using percentage change of data in relation to control measurements, within-group comparisons for 0-10 $\mathrm{min}$. (T1) and 50-60 min (T2) data were performed by Friedman tests, followed by Wilcoxon tests at 95\% confidence levels. To explore the effects of LED versus QTH on nerve conduction, between-group comparisons were performed by Mann-Whitney $U$ tests at $95 \%$ confidence level. Between-group pair-wise comparisons of cements were also undertaken by Kruskal Wallis test followed by Mann-Whitney $U$ tests at $95 \%$ confidence levels.

\section{RESULTS}

\section{Within-group comparisons}

Descriptive statistics of tests groups and $P$ values for within-group comparisons are presented in Tables 2 and 3, respectively. The differences in $\mathrm{C}-\mathrm{T} 2$ for cAPs were significant in all groups $(P<.05)$, although some groups showed similarity between C-T1 and T1-T2 data (P>.05). Likewise, differences in C-T2 for TcAP were significant between groups $(P<.05)$, except for Variolink-QTH $(P=$.959). In addition, the differences in C-T1 and T1-T2 were significant in most groups $(P<.05)$,

Table 1. Resin cements used in the study.

\begin{tabular}{|c|c|c|c|c|}
\hline Materials & Ingredients & Batch No & Manufacturer & Abbreviation \\
\hline Panavia F & $\begin{array}{l}\text { 10-Methacryloyloxydecyl dihydrogen phosphate } \\
\text { Hydrophobic aromatic dimethacrylate } \\
\text { Hydrophobic aliphatic dimethacrylate } \\
\text { Hydrophilic aliphatic dimethacrylate } \\
\text { Silanated silica filler } \\
\text { Silanated colloidal silica } \\
\text { dl-Camphorquinone } \\
\text { Silanated barium glass filler } \\
\text { Initiators } \\
\text { Accelerators } \\
\text { Pigments } \\
\text { Sodium fluoride }\end{array}$ & 41168 & Kuraray Dental INC. & Panavia \\
\hline RelyX ARC & $\begin{array}{l}\text { Fillers } 60-70 \% \\
\text { Triethylene glycoldimethacrylate } \% 10-20 \\
\text { Bis-GMA } \% 10-20 \\
\text { Silanated filler } \% 1-10\end{array}$ & 20061204 & 3M, ESPE & RelyX \\
\hline Variolink II & $\begin{array}{l}\text { Paste of dimethacrylates, inorganic fillers, ytterbiumtrifluoride, } \\
\text { initiators, stabilizers and pigments } \\
\qquad \begin{array}{c}10-14 \% \text { Bis-GMA } \\
5-7 \% \text { Triethylene glycoldimethacrylate } \\
5-7 \% \text { Urethanedimethacrylate } \\
<1 \% \text { Benzoylperoxide }\end{array}\end{array}$ & J03326 & Ivoclar Vivadent & Variolink \\
\hline
\end{tabular}


although similar data was obtained for the Variolink-QTH group (P>.05) (Table 3). The differences in T1-T2 and C-T2 data for Dp were significant in all groups $(P<.05)$, except for $C-T 2$ data of Panavia-QTH (P>.05). Some groups showed similarity between C-T1 data (P>.05) (Table 3). The differences in C-T2 for Rp values were significant only for Panavia-QTH and Variolink-QTH $(P<.05)$ and some groups showed similarity between C-T1 and T1-T2 data (P>.05).

\section{Between-group comparisons}

Between-group comparisons of LED versus QTH on nerve conduction (cAP, TcAP, Dp, and Rp) showed that the differences between groups were significant $(P<.05)$, except for TcAP and Dp of RelyX ( $P=.353$ and $P=.247$, respectively) during $T 1, D p$ of Rely $X(P=.912)$ during $T 2$, and Rp of Variolink during T1 $(P=.075)$. $P$ values for between-group comparisons are presented in Table 4. In the LED group, the differences between groups in T1 and T2 were significant for most variables $(P<.05)$, except TcAP, Dp, and Rp data of Panavia and Variolink in T1 in and RelyX and Variolink in T2 (P>.05). In the QTH group, the outcome was similar for most variables in T1 ( $P>$.05), whereas significant differences were observed at the termination of the experiments $(P<.05)$.

\section{DISCUSSION}

The mechanism of neural response and nerve conduction basically depend on depolarizationrepolarization of nerve activities, which are known to be related to precise regulation of sodium and potassium gateways. In the context of biomaterial-nerve tissue reactions, alterations of depolarization and repolarization are crucial, as they influence signal transduction through the nerve.

Table 2. Descriptive statistics and percentage change of data acquired from sciatic nerves before (control) and after contact with resin cements during T1 and T2

\begin{tabular}{|c|c|c|c|c|c|c|c|c|c|c|c|c|c|}
\hline \multirow{2}{*}{ cAPs } & & \multicolumn{4}{|c|}{ Control } & \multicolumn{4}{|c|}{$\mathrm{T} 1$} & \multicolumn{4}{|c|}{ T2 } \\
\hline & & TCAP & Dp & $\mathrm{Rp}$ & cAPs & TCAP & Dp & $\mathrm{Rp}$ & cAPs & TcAP & Dp & $\mathrm{Rp}$ & \\
\hline \multirow{4}{*}{ Pan-LED } & Mean \pm SD & $1.09 \pm 0.02$ & $1.62 \pm 0.03$ & $0.81 \pm 0.01$ & $0.81 \pm 0.03$ & $0.94(0.02)$ & $1.53 \pm 0.04$ & $0.77 \pm 0.02$ & $0.76 \pm 0.02$ & $0.75 \pm 0.02$ & $1.41 \pm 0.03$ & $0.59 \pm 0.04$ & $0.82 \pm 0.03$ \\
\hline & Minimum & 1.05 & 1.59 & 0.78 & 0.75 & 0.90 & 1.44 & 0.73 & 0.70 & 0.72 & 1.35 & 0.53 & 0.77 \\
\hline & Maximum & 1.12 & 1.69 & 0.83 & 0.87 & 0.97 & 1.58 & 0.82 & 0.79 & 0.78 & 1.47 & 0.67 & 0.87 \\
\hline & $\%$ change & 100 & 100 & 100 & 100 & 85.95 & 94.27 & 95.27 & 93.46 & 68.91 & 87.16 & 72.71 & 101.72 \\
\hline \multirow{4}{*}{ Pan-QTH } & Mean \pm SD & $0.37 \pm 0.01$ & $0.73 \pm 0.01$ & $0.36 \pm 0.01$ & $0.36 \pm 0.01$ & $0.37(0.01)$ & $0.73 \pm 0.01$ & $0.37 \pm 0.01$ & $0.36 \pm 0.01$ & $0.32 \pm 0.01$ & $0.70 \pm 0.00$ & $0.35 \pm 0.01$ & $0.34 \pm 0.00$ \\
\hline & Minimum & 0.35 & 0.71 & 0.34 & 0.34 & 0.35 & 0.72 & 0.35 & 0.34 & 0.31 & 0.67 & 0.34 & 0.33 \\
\hline & Maximum & 0.40 & 0.75 & 0.38 & 0.39 & 0.41 & 0.75 & 0.38 & 0.39 & 0.34 & 0.72 & 0.36 & 0.36 \\
\hline & $\%$ change & 100 & 100 & 100 & 100 & 100.79 & 100.38 & 101.86 & 99.35 & 87.14 & 95.11 & 97.72 & 94.28 \\
\hline \multirow{4}{*}{ RelyX-LED } & Mean $\pm S D$ & $0.08 \pm 0.03$ & $1.32 \pm 0.03$ & $0.59 \pm 0.01$ & $0.72 \pm 0.02$ & $0.13(0.00)$ & $1.35 \pm 0.02$ & $0.60 \pm 0.01$ & $0.74 \pm 0.01$ & $0.20 \pm 0.00$ & $1.27 \pm 0.03$ & $0.54 \pm 0.01$ & $0.73 \pm 0.03$ \\
\hline & Minimum & 0.03 & 1.26 & 0.57 & 0.68 & 0.13 & 1.31 & 0.58 & 0.71 & 0.20 & 1.20 & 0.50 & 0.68 \\
\hline & Maximum & 0.12 & 1.35 & 0.61 & 0.75 & 0.13 & 1.37 & 0.61 & 0.76 & 0.21 & 1.35 & 0.57 & 0.79 \\
\hline & $\%$ change & 100 & 100 & 100 & 100 & 197.62 & 102.28 & 101.85 & 102.69 & 305.19 & 96.60 & 91.85 & 100.34 \\
\hline \multirow{4}{*}{ RelyX-QTH } & Mean \pm SD & $0.001 \pm 0.03$ & $1.41 \pm 0.05$ & $0.62 \pm 0.03$ & $0.79 \pm 0.03$ & $-0.05(0.0)$ & $1.41 \pm 0.01$ & $0.66 \pm 0.02$ & $0.75 \pm 0.0$ & $-0.05 \pm 0.0$ & $1.51 \pm 0.02$ & $0.72 \pm 0.02$ & $0.79 \pm 0.02$ \\
\hline & Minimum & -0.05 & 1.34 & 0.57 & 0.75 & -0.06 & 1.39 & 0.62 & 0.73 & -0.10 & 1.47 & 0.69 & 0.75 \\
\hline & Maximum & 0.04 & 1.50 & 0.68 & 0.83 & -0.05 & 1.45 & 0.69 & 0.76 & -0.03 & 1.56 & 0.75 & 0.83 \\
\hline & $\%$ change & 100 & 100 & 100 & 100 & 48.31 & 100.09 & 105.33 & 95.94 & 61.53 & 107.22 & 115.28 & 100.74 \\
\hline \multirow{4}{*}{ Vario-LED } & Mean \pm SD & $0.04 \pm 0.00$ & $2.16 \pm 0.07$ & $1.05 \pm 0.04$ & $1.11 \pm 0.04$ & $0.04(0.00)$ & $2.05 \pm 0.04$ & $0.98 \pm 0.02$ & $1.06 \pm 0.03$ & $0.05 \pm 0.00$ & $2.05 \pm 0.05$ & $0.95 \pm 0.02$ & $1.09 \pm 0.05$ \\
\hline & Minimum & 0.02 & 2.05 & 0.98 & 1.03 & 0.04 & 1.98 & 0.92 & 1.00 & 0.05 & 1.99 & 0.91 & 1.03 \\
\hline & Maximum & 0.04 & 2.25 & 1.11 & 1.15 & 0.04 & 2.14 & 1.02 & 1.12 & 0.05 & 2.15 & 0.99 & 1.21 \\
\hline & $\%$ change & 100 & 100 & 100 & 100 & 96.11 & 95.17 & 93.74 & 96.14 & 130.43 & 94.95 & 90.76 & 98.57 \\
\hline \multirow{4}{*}{ Vario-QTH } & Mean $\pm S D$ & $2.98 \pm 0.04$ & $1.57 \pm 0.01$ & $1.07 \pm 0.01$ & $0.49 \pm 0.01$ & $3.00(0.03)$ & $1.57 \pm 0.01$ & $1.07 \pm 0.01$ & $0.49 \pm 0.02$ & $2.68 \pm 0.02$ & $1.57 \pm 0.01$ & $1.26 \pm 0.01$ & $0.30 \pm 0.02$ \\
\hline & Minimum & 2.89 & 1.53 & 1.05 & 0.46 & 2.97 & 1.54 & 1.04 & 0.45 & 2.64 & 1.55 & 1.24 & 0.28 \\
\hline & Maximum & 3.04 & 1.59 & 1.09 & 0.52 & 3.07 & 1.61 & 1.09 & 0.56 & 2.75 & 1.59 & 1.29 & 0.35 \\
\hline & $\%$ change & 100 & 100 & 100 & 100 & 100.96 & 100.17 & 99.97 & 100.63 & 89.99 & 100.20 & 118.18 & 61.43 \\
\hline
\end{tabular}

T1: Data acquired during 0-10 minutes; T2: Data acquired during 50-60 minutes; Pan-LED: Panavia F polymerized by LED; Pan-QTH: Panavia F polymerized by QTH; RelyXLED: RelyX ARC polymerized by LED; RelyX-QTH: RelyX ARC polymerized by QTH; Vario-LED: Variolink II polymerized by LED; Vario-QTH: Variolink II polymerized by QTH. 
Any alteration during depolarization or repolarization and initiation of a CAP (TCAP) could be interpreted as alteration in the function of $\mathrm{Na}-\mathrm{K}$ gates in the cell membrane. In the present study, TcAP, $D p$, and Rp of all cements showed changes in the range of $5-10 \%$, although the Dp of Panavia-LED in T2 and Rp of Variolink in T2 had $27.29 \%$ and $38.57 \%$ decrease, respectively.

Any material causing more than $50 \%$ alteration of cAPs without recovery lirreversible inhibition of nerve conductance) should be interpreted as neurotoxic. ${ }^{18}$ In the present study, a change of $197 \%$ was observed for RelyX-LED for T1, which continued to rise up to $305.19 \%$. Likewise, reduction of cAPs by $51.69 \%$ were observed for RelyX-QTH group and recovered only by $13.22 \%$ (Table 2 ). This result suggests that RelyX - polymerized either by LED or QTH - has a high potential of eliciting irreversible inhibition of cAPs of rat sciatic nerves. The drastic change in cAPs could be attributed to 10-20\% TEGDMA content of RelyX, which also has a strong potential of leading to apoptosis. ${ }^{5-8}$ How- ever, the dose-dependent neurotoxic effects of TEGDMA is unknown and remain as an open field for investigation.

Ideally, resin cement is expected to have converted all of its monomer to polymer upon polymerization, but under conventional irradiation, all dimethacrylate monomers suffer from considerable amount of residual monomer with a degree of conversion between 55\%-75\%. ${ }^{21,22}$ Although RelyX ARC cement has higher degree of conversion in comparison with Panavia and Variolink, ${ }^{23}$ the TEGDMA content in Variolink is $7-10 \%$ and it is not present in Panavia. Therefore, in the context of cytotoxicity, a low degree of conversion is not always an indicator of release of toxic substances due to inadequate development of the polymer network. In the present study, the percentage changes in cAPs of other resin cements could not be inferred as neurotoxic effects but rather reversible inhibition of cAPs, as full recovery was not observed. ${ }^{20}$ It seems that Panavia and Variolink polymerized by QTH had the lowest effect on nerve conductance.

Table 3. P values for within-group comparisons.

\begin{tabular}{|c|c|c|c|c|c|c|c|c|c|c|c|c|}
\hline & & cAP & & & TcAP & & & $\mathrm{Dp}$ & & & $\mathrm{Rp}$ & \\
\hline & CT1 & C-T2 & T1-T2 & C-T1 & C-T2 & T1-T2 & C-T1 & C-T2 & $\mathrm{T} 1-\mathrm{T} 2$ & C-T1 & C-T2 & $\mathrm{T} 1-\mathrm{T} 2$ \\
\hline Pan-LED & 0.005 & 0.005 & 0.005 & 0.005 & 0.005 & 0.007 & 0.005 & 0.005 & 0.005 & 0.007 & $0.508^{*}$ & 0.005 \\
\hline Pan-QTH & $0.878^{*}$ & 0.005 & 0.005 & $0.859^{*}$ & 0.005 & 0.005 & $0.359 *$ & $0.285^{*}$ & 0.007 & $0.799 *$ & 0.007 & 0.022 \\
\hline RelyX-LED & 0.005 & 0.005 & 0.005 & 0.007 & 0.037 & 0.007 & 0.037 & 0.005 & 0.005 & 0.011 & $0.799 *$ & $0.109 *$ \\
\hline RelyX-QTH & 0.005 & 0.037 & $0.093^{*}$ & $0.959 *$ & 0.008 & 0.005 & 0.047 & 0.005 & 0.005 & 0.028 & $0.646^{*}$ & 0.013 \\
\hline Vario-LED & $0.139 *$ & 0.005 & 0.005 & 0.013 & 0.013 & $0.575^{*}$ & 0.009 & 0.007 & 0.017 & 0.047 & $0.386^{*}$ & $0.444^{*}$ \\
\hline Vario-QTH & $0.169 *$ & 0.005 & 0.005 & $0.575^{*}$ & $0.959^{*}$ & $0.959 *$ & $0.878^{*}$ & 0.005 & 0.005 & $0.959 *$ & 0.005 & 0.005 \\
\hline
\end{tabular}

*: not significant; C:Control; T1: Data acquired during 0-10 minutes; T2: Data acquired during 50-60 minutes; Pan-LED: Panavia F polymerized by LED; Pan-QTH: Panavia F polymerized by QTH; RelyX-LED: RelyX ARC polymerized by LED; RelyX-QTH RelyX ARC polymerized by QTH; Vario-LED: Variolink II polymerized by LED; Vario-QTH: Variolink II polymerized by QTH.

Table 4. P values for between-group comparisons.

\begin{tabular}{|c|c|c|c|c|c|c|c|c|c|}
\hline & & \multicolumn{4}{|c|}{ T1 } & \multicolumn{4}{|c|}{$\mathrm{T} 2$} \\
\hline & & cAP & TcAP & Dp & $\mathrm{Rp}$ & cAP & TcAP & $D p$ & $\mathrm{Rp}$ \\
\hline \multirow{3}{*}{ LED } & Pan-RelyX & 0.00 & 0.00 & 0.00 & 0.00 & 0.00 & 0.00 & 0.00 & $0.631 *$ \\
\hline & Pan-Vario & 0.00 & $0.912^{*}$ & $0.247^{*}$ & $0.218^{*}$ & 0.00 & 0.00 & 0.00 & $0.28 *$ \\
\hline & RelyX-Vario & 0.00 & 0.001 & 0.001 & 0.007 & 0.00 & $0.436 *$ & $0.579 *$ & $0.529 *$ \\
\hline \multirow{3}{*}{ QTH } & Pan-RelyX & 0.00 & $0.94^{*}$ & $0.226^{*}$ & $0.406^{*}$ & 0.028 & 0.00 & 0.00 & 0.023 \\
\hline & Pan-Vario & $0.88^{*}$ & $0.762 *$ & $0.226^{*}$ & $0.545^{*}$ & 0.049 & 0.001 & 0.00 & 0.00 \\
\hline & RelyX-Vario & 0.00 & $0.762^{*}$ & $0.131 *$ & $0.112^{*}$ & 0.023 & 0.004 & $0.226 *$ & 0.00 \\
\hline
\end{tabular}

*: not significant; T1: Data acquired during 0-10 minutes; T2: Data acquired during 50-60 minutes; PAN: Panavia F; Vario: Variolink II 
However, it should be taken into account that polymerization of these cements by LED resulted in approximately a $30 \%$ change in cAPs at the termination of the experiments.

Comparison of LED with QTH showed that the differences were statistically significant for cAPs of all cements and for most variables. Nerve conductance of Panavia and Variolink polymerized by QTH showed a more stable time-dependent behavior of nerve conductance in comparison with LED-polymerized specimens of these cements. Overall, QTH-polymerized specimens tended to show better results, although a clear advantage of QTH over LED was not discernable in the present study.

\section{CONCLUSIONS}

The present results suggest that RelyX polymerized by either LED or QTH leads to irreversible effects on nerve conductance. Panavia and Variolink polymerized by both techniques lead to reversible alteration of nerve function. These cements polymerized by QTH show a more stable nerve conductance over time in comparison with LED-polymerization.

\section{REFERENCES}

1. Geurtsen W. Biocompatibility of resin-modified filling materials. Crit Rev Oral Biol Med 2000;11:333-355.

2. Stanislawski L, Daniau X, Lauti A, Goldberg M. Factors responsible for pulp cell cytotoxicity induced by resinmodified glass ionomer cements. J Biomed Mater Res 1999;48:277-288.

3. Caughman WF, Chan DC,Rueggeberg FA. Curing potential of dual-polymerizable resin cements in simulated clinical situations. J Prosthet Dent 2001;86:101-106.

4. Peutzfeldt A. Dual-cure resin cements: in vitro wear and effect of quantity of remaining double bonds, filler volume, and light curing. Acta Odontol Scand 1995;53:29-34.

5. Bakopoulou A, Tsiftsoglou A, Galaktidou G, Markala D, Triviai I,Garefis P. Patterns of cell death and cell cycle profiles of cultured WEHI 13 var fibroblasts exposed to eluates of composite resins used for direct and indirect restorations. Eur J Oral Sci 2007;115:397-407.

6. Becher R, Kopperud HM, Al RH, Samuelsen JT, Morisbak $E$, Dahlman $H J$, et al. Pattern of cell death after in vitro exposure to GDMA, TEGDMA, HEMA and two compomer extracts. Dent Mater 2006;22:630-640.
7. Janke V, von Neuhoff $N$, Schlegelberger B, Leyhausen G,Geurtsen W. TEGDMA causes apoptosis in primary human gingival fibroblasts. J Dent Res 2003;82:814-818.

8. Samuelsen JT, Dahl JE, Karlsson S, Morisbak E,Becher R. Apoptosis induced by the monomers HEMA and TEGDMA involves formation of ROS and differential activation of the MAP-kinases p38, JNK and ERK. Dent Mater 2007;23:34-39.

9. Kleinsasser NH, Schmid K, Sassen AW, Harreus UA, Staudenmaier R, Folwaczny $M$, et al. Cytotoxic and genotoxic effects of resin monomers in human salivary gland tissue and lymphocytes as assessed by the single cell microgel electrophoresis (Comet) assay. Biomaterials 2006;27:1762-1770.

10. Schweikl H, Schmalz G,Rackebrandt K. The mutagenic activity of unpolymerized resin monomers in Salmonella typhimurium and V79 cells. Mutat Res 1998;415:119-130.

11. Schweikl H, Schmalz G,Spruss T. The induction of micronuclei in vitro by unpolymerized resin monomers. $J$ Dent Res 2001;80:1615-1620.

12. Schweikl H, Spagnuolo G,Schmalz G. Genetic and cellular toxicology of dental resin monomers. J Dent Res 2006;85:870-877.

13. de Souza Costa CA, Hebling J,Randall RC. Human pulp response to resin cements used to bond inlay restorations. Dent Mater 2006;22:954-962.

14. Eldeniz AU, Mustafa K, Orstavik D,Dahl JE. Cytotoxicity of new resin-, calcium hydroxide- and silicone-based root canal sealers on fibroblasts derived from human gingiva and L929 cell lines. Int Endod J 2007;40:329-337.

15. Ferracane JL. Elution of leachable components from composites. J Oral Rehabil 1994;21:441-452.

16. Peumans $M$, Van Meerbeek $B$, Lambrechts $P$, Vanherle G,Quirynen M. The influence of direct composite additions for the correction of tooth form and/or position on periodontal health. A retrospective study. J Periodontol 1998;69:422-427.

17. Szep S, Kunkel A, Ronge K,Heidemann D. Cytotoxicity of modern dentin adhesives--in vitro testing on gingival fibroblasts. J Biomed Mater Res 2002;63:53-60.

18. Cehreli ZC, Onur MA, Tasman F, Gumrukcuoglu A,Artuner $H$. Effects of current and potential dental etchants on nerve compound action potentials. J Endod 2002;28:149-151.

19. Onur MA, Cehreli ZC, Tasman F,Gumrukcuoglu A. Neurotoxic effects of fifth-generation dentin adhesives on rat sciatic nerve. J Endod 2001;27:676-678.

20. Cehreli MC, Onur MA,Sahin S. Effects of hydroxyapatitecoated and commercially pure titanium oral implant surfaces on compound nerve action potentials. Clin Oral Implants Res 2003;14:269-272. 
21. Eliades GC, Vougiouklakis GJ,Caputo AA. Degree of double bond conversion in light-cured composites. Dent Mater 1987;3:19-25.

22. Silikas N, Eliades G,Watts DC. Light intensity effects on resin-composite degree of conversion and shrinkage strain. Dent Mater 2000;16:292-296.

23. Tezvergil-Mutluay A, Lassila LV,Vallittu PK. Degree of conversion of dual-cure luting resins light-polymerized through various materials. Acta Odontol Scand 2007;65:201205. 